\title{
A Novel Natural Product for Bone Regeneration in Dentistry - A Review
}

\author{
Mokshi Jain ${ }^{1}$, Nivedhitha M.S. ${ }^{2}$, Deepak S33, Rajesh Kumar S. ${ }^{4}$ \\ ${ }^{1}$ Department of Conservative Dentistry and Endodontics, Saveetha Dental College, Chennai, Tamil Nadu, India. \\ 2Department of Conservative Dentistry and Endodontics, Saveetha Dental College and Hospitals, Saveetha Institute of \\ Medical and Technical Sciences (SIMATS), Chennai, Tamil Nadu, India. ${ }^{3}$ Department of Conservative Dentistry and \\ Endodontics, Saveetha Dental College and Hospitals, Saveetha Institute of Medical and Technical Sciences (SIMATS), \\ Chennai, Tamil Nadu, India. ${ }^{4}$ Department of Pharmacology, Saveetha Dental College and Hospitals, Save etha Institute \\ of Medical and Technical Sciences (SIMATS), Chennai, Tamil Nadu, India.
}

\section{ABSTRACT}

\section{BACKGROUND}

Herbal medicine has been regarded as a safer and more natural method to promote health and alleviate illness and has gained notable popularity. Plants continue to be the primary source of new chemicals and drugs and hence play a pivotal role in the continual improvement in therapeutic medicine. India has a huge asset of indigenous plants and minerals which have been broadly used for therapeutic claim. One such plant which has immense benefits derived from it is Cissus quadrangularis [CQ] colloquially known as hadjod or pirandai. CQ is one of the most significant plants. However, practically the entirety of its parts are utilized in medicine among which seeds, stems, roots, and shoots are the most significant parts. Concentrates and powders of Cissus quadrangularis have been utilized for a long time to aid bone and tissues healing, as an antioxidant, for relieving pain \& swelling, to fight against infection, as an anabolic, and also to help in weight reduction. The most important usage has been for bone regeneration and fracture healing. Numerous studies have been done to prove its pharmacological effects and to substantiate its use clinically. The aim of this review is to elaborate on CQ, its ethnopharmacology, phytochemistry and principle constituents, pharmacological actions, formulations and to review previous literature such as animal studies, in vitro studies and clinical trials to understand in detail about the applications of this plant in medicine and dentistry.

\section{KEY WORDS}

Cissus quadrangularis, Pharmacology, Herbal, Bone Regeneration
Corresponding Author: Dr. Nivedhitha M.S,

162, Poonamallee High Road, Chennai - 6000077,Tamil Nadu, India

E-mail: nivea16@hotmail.com

DOI: $10.14260 / \mathrm{jemds} / 2020 / 617$

How to Cite This Article:

Jain M, Nivedhitha M.S., Deepak S, et al. A novel natural product for bone regeneration in dentistry - a review. $J$ Evolution Med Dent Sci 2020;9(38):28332838, DOI: $10.14260 /$ jemds/2020/617

Submission 04-05-2020,

Peer Review 27-07-2020,

Acceptance 04-08-2020,

Published 21-09-2020.

Copyright (C) 2020 JEMDS. This is an open access article distributed under Creative Commons Attribution License [Attribution 4.0 International (CC BY 4.0)] 


\section{BACKGROUND}

In recent years, the traditional sources of medicines have become an important adjunct to allopathic therapy. There has been an overwhelming increase in the usage of plant based herbal products in developed countries which has resulted in an exponential growth of herbal products worldwide. WHO revealed that practically $80 \%$ of the word populace relies on traditional sources of medicine. ${ }^{1}$ Plants continue to be the primary source of new chemicals and drugs and hence play a pivotal role in the continual improvement in therapeutic medicine. India has a huge asset of indigenous plants and minerals which have been broadly used for therapeutic claim. Herbal medicine has been regarded as a safer and more natural method to promote health and alleviate illness and has gained notable popularity.

One such plant which has immense benefits derived from it is Cissus quadrangularis, colloquially known as hadjod or pirandai. It is endemic to the tropical districts of the Indian subcontinent and zones of Malaysia, Sri Lanka, West Africa, and Java. It has gained the attention of researchers due to its inherent analgesic, anti-inflammatory, antioxidant activity, bone healing effect and other antibiotic properties. ${ }^{2}$ Due to its promising potential, it has been incorporated in various forms for the management of many conditions in various fields. The most important usage has been for bone regeneration and fracture healing. Numerous studies have been done to prove its pharmacological effects and to substantiate its use clinically.

The aim of this review is to elaborate on Cissus quadrangularis [CQ], its ethnopharmacology and review previous literature such as animal studies, in vitro studies and clinical trials to understand in detail about the applications of this plant in medicine and dentistry.

\section{ABOUT CISSUS QUADRANGULARIS}

\section{Scientific Classification}

1. Kingdom: Plantae

2. Division: Magnoliophyta

3. Class: Magnoliopsida

4. Order: Vitales

5. Family: Vitaceae

6. Genus: Cissus

7. Species: quadrangularis

\section{Botanical Description}

CQ usually referred as Veldt Grape or Devil's backbone, Asthisandhani in Sanskrit and Hadjod in Hindi due to its bone healing properties. It is a succulent plant or vine belonging to family Vitaceae. The stem of the plant is fleshy and usually quadrangular and 4 winged. The internodes are $4-5 \mathrm{~cm}$ long, $1-2 \mathrm{~cm}$ thick with infrequent tendril at the nodes. The outer surface of the plant is generally smooth, glabrous, buff hued with a greenish hint, angular segments are rosy earthy colour, and the plant has no taste or smell. The leaves are basic 2 - 2.5 $\mathrm{cm}$ long, are broadly ovate or reniform, 3 - 7 lobed with the petioles are $6-12 \mathrm{~mm}$ long. The blossoms are in the blink of an eye pedunculated cymes with spreading umbellate branches. Calyx is little, cup formed, deciduous in nature. The petals are four in number, mostly short and ovate in shape. ${ }^{3}$

\section{Ethnopharmacology}

CQ is known as "Asthi Samhara" in Sanskrit which actually means pacification of bones. Most of the local names given to this plant are attributed to its uses. The stem of this plant is used in Ayurveda for its laxative, anthelminthic and analgesic properties. ${ }^{4}$ The Unani system of medicine has reported internal administration of the plant and has also advocated its use topically for bone fracture healing. Siddha medicine has made use of its stem which is said to have stomachic properties and is used for treating digestive ailments. The paste from the stem is used for treating asthmatic patients and applied internally and externally for joining fractured bones. ${ }^{5}$ The powder produced using the remains of its shoots is given in cases of dyspepsia. ${ }^{6}$ The powder produced using its underlying root is used as bone plaster and in the treatment of gout and constipation. ${ }^{7}$

\section{Phytochemistry and Principle Constituents}

The major bioactive components of CQ which are responsible for its pharmacological effects are ascorbic acid, carotene, phytosterol substances, calcium, flavonoids, vitamins, enzymes, nicotinic acid, tyrosine, alkaloids, resveratrol, piceatannol, pallidal, parthenocissin, quadrangularis, and triterpenoids. Investigations showed presence of five known compounds including ecosyl eicosanoate, Tetra triacontanoic acid, tetratriacotanol, $\alpha \beta$-amyrin (a), $\beta$-sitosterol (b), Polyphenols such as Genistein (f), Quercetin (m) and Daidzein (c) has also been reported. ${ }^{8}$ Friedelin (e), which is a phytoestrogen found in CQ extract has been implicated in the increase of A.L.P activity and increased rate of mineralization through estrogenic receptors. ${ }^{9}$ The stem has two steroidal principles and two asymmetric tetracyclic triterpenoids. The presence of $\beta$-sitosterol, $\delta$ - amyrin, $\delta$-amyrone, and flavonoids (quercetin) having different potential metabolic and physiological effects has also been reported and the stem has revealed unique stilbene derivatives, which are termed quadrangularins $\mathrm{A}, \mathrm{B}$ and C. ${ }^{10} \mathrm{CQ}$ is rich source of beta carotene and vitamin C. Analysis has shown that these plants also contain ascorbic acid at a concentration of $479 \mathrm{mg}$, and carotene 267 units per $100 \mathrm{~g}$ of freshly prepared paste, in addition to calcium oxalate. ${ }^{11}$

\section{Pharmacological Actions}

The pharmacological actions that are mediated by the chemical constituents can be listed as follows-

1. Anti-Osteoporotic Activity - Several studies have certified the usage of $\mathrm{CQ}$ in the field of bone remineralisation and fracture healing. A study using extracts (petroleum ether) of CQ to check the bone cell proliferation was done using male wiser rat's bone marrow mesenchymal cells. These cells were allowed to proliferate in two individual media, one basal media and the other was osteogenic media with and without the addition of extract (petroleum ether) of CQ. It was seen that the rate of proliferation and differentiation into osteoblasts (identified by using alkaline 
phosphatase as a biomarker) is much greater in the media treated with extract.12 The phytogenic steroids found in CQ may act on oestrogen receptors of bone cells and also helps in stimulating osteoblastogenesis. The active constituents of CQ utilize Wnt-LRP5- $ß$-catenin signalling pathway to stimulate the proliferation and promote new bone formation.

2. Anti-Inflammatory Activity - An examination indicated that the active portion of CQ shows a compelling decrease in COX, nitric oxide synthase and TNF-alpha levels in a dose dependent manner which shows its inflammatory property. 13

3. Analgesic and Antipyretic Activity - Studies have proved that CQ is as potent as aspirin in treatment of acetic acid induced writhing in mice, formalin test and tail-flick test in rats. The plant is also effective in the treatment of yeast infection induced hyper-pyrexia. ${ }^{14}$

4. Antioxidant Activity - CQ's antioxidant activity was proved with various in-vitro and in-vivo studies. The first in vitro study assessed the erythrocyte lipid peroxidation rate in which, the marker used was Thiobarbituric acid reactive substance (TBARS) and reference drug used was Butylated hydroxytoluene (BHT). In another study, the reference drug used was Catechin where they incorporated the discoloration of 1,1-diphenyl-2-picrylhydrazyl radical (DPPH). In both the studies, the CQ's antioxidant activity was seen as nearly comparable to reference drugs. In-vivo, animal studies showed that rats treated with CQ extract had a lower level of aspartate amino - transferase, Superoxide dismutase, catalase, Glutathione peroxidase as biomarkers. ${ }^{12}$ CQ also possesses Hepatoprotective activity, ${ }^{15}$ Antidiabetic, ${ }^{16}$ Antiviral activity, ${ }^{17}$ Antibacterial activity, ${ }^{18}$ Antifungal activity, Anti-ulcer and gastroprotective activity ${ }^{19}$ Anti-obesity and anorexiant activity. ${ }^{20}$

\section{Formulations of Cissus quadrangularis}

Some studies have also compiled the different actions which are incorporated in various extracts of CQ. The activity carried out by different extracts can be listed as follows ${ }^{21}$

1. Ethanol Extract - Antiosteoporotic and Osteoblastic activity.

2. Methanol Extract - Antimicrobial and antioxidant activity, anti-ulcer activity, osteoblastic activity.

3. Ethyl acetate Extract - Gene expression, Antioxidant and anti-microbial activity.

4. Aqueous Extract - Antimicrobial activity, antiparasitic activity, CNS depressant activity, anti-epileptic activity.

5. Active Acetone Fraction - Anti-inflammatory activity.

6. Petroleum Ether Extract - Anti-osteoporotic activity.

7. Chloroform Extract - Anti-bacterial activity.

8. Silver Nanoparticles - Silver nanoparticles from CQ displayed antimicrobial, anti-inflammatory, immunomodulatory and hypolipidemic activities with no genuine reactions. ${ }^{22}$

\section{APPLICATIONS OF CISSUS QUADRANGULARIS}

\section{Medical Uses}

Osteoporosis - Osteoporosis is defined as chronic, progressive condition associated with micro-architectural deterioration of bone tissue that result in low bone mass. Numerous in-vivo and animal studies have been done to prove its anti-osteoporotic property.

The component behind this activity is its ability to improve bone marrow mesenchymal stem cell proliferation and encourage osteoblastogenesis. BMMSCs are the source of bone-forming osteoblasts. The extracts of CQ (petroleum ether) can assist in the differentiation of mesenchymal stem cells into osteoblasts in a dose-dependent manner. Within the sight of osteogenic media, the plant extract has demonstrated expanded activity. The plant extract additionally encouraged extracellular matrix mineralization, which was progressively eminent within the sight of osteogenic media. At long last, the nearness of plant extract in the control and osteogenic media stimulated the proliferation rate of mesenchymal stem cells. Bhagath Kumar Potu et al,12 examined that alkaline phosphatase activity, the most generally perceived biomarker for osteoblast action, was improved by a short treatment with CQ. In clinical experiments showed that CQ advances alkaline phosphatase activity and expands collagen synthesis for healing of the fracture. He additionally proposes that the oil ether portion may contain dynamic constituents that stimulate osteoblast differentiation and its bioactivity. The phytogenic steroid seen in CQ aids in stimulating osteoblastogenesis and follow up on bone cell's oestrogen receptors.

Reduction of Joint Pain - Arduous, high-volume practice is identified with swelling and joint pain. CQ has been portrayed to show anti-inflammatory activity. In a study led by Blossomer et al, men between the ages of 20 and 46 years, who apparently experienced interminable joint pain because of arduous exercise, taken part in the pilot study. CQ 3200 mg was offered day by day to all men for about two months. CQ was viable in decrease of joint pain. ${ }^{23}$

Fracture Healing - Fractures are ordinarily dealt with reduction, retention and rehabilitation for appropriate union and this process takes about nearly a month for complete healing. Ayurvedic medicine has listed many herbs which accelerate this healing process, one such herb being CQ. Studies have shown earlier calcification and callus formation due to increased rate of collagen fibres formation. ${ }^{24}$ It also helps in building of chemical composition of the bone with the help of mucopolysaccharides, collagen, calcium and phosphorus. ${ }^{25}$ Systemic use of CQ shortens the bone healing duration by about 2 weeks. ${ }^{26}$ Studies have also shown that CQ helps in management of Obesity. ${ }^{27}$ 


\section{Dental Uses}

Periodontal Osseous Defects - Bone grafts and guided tissue regeneration (GTR) is used for restoring bony defects in periodontal diseases. In the course of recent years, hydroxyapatite (HA) and related calcium phosphate is being utilized as bone substitutes as their crystalline and chemical compositions are firmly unified to the mineral parts of the bone. CQ was considered an effective natural alternative because of its capacity to help in bone regeneration. In a study by Nand Lal et al, ${ }^{28}$ the osteogenic potential of HA, CQ and oxidised cellulose membrane (OCM) was compared to healing of normal bone. A total of 20 patients with periodontitis of age group between 20-40 years were included. Inclusion criteria were deep periodontal pockets, vertical bony defects with two- or three-walled involvement and probing depth $\geq 5 \mathrm{~mm}$ clinically. Infrabony defects were divided into four groups (Group I - control, Group II - HA, Group III - CQ and IV received OCM.), so that each group consists of five bony defects. Periodically the level of attachment and probing depth was measured after surgery. Following a half year, the deformities were re-exposed using crevicular incisions. CQ showed better osseous healing than the control group.

Improved Stability of Orthodontic Implants - Various natural products were utilized previously, for controlling bone metabolism trying to advance anabolic impact or suppressing the catabolism of bone. In a study done by Hamed Al-Sultan et al, a total of mature 25 male rabbits, characterized into 5 groups (1 control and 4-trial). A total of 15 orthodontic implants were placed in the tibia bone of each rabbit, with two implants in each tibia. The natural products used in this study were CQ $1000 \mathrm{mg} / \mathrm{Kg}$, Curcumin $15 \mathrm{mg} / \mathrm{Kg}$, Nigella Sativa oil $0.5 \mathrm{~mL} / \mathrm{Kg}$, and Virgin coconut oil $2 \mathrm{~mL} / \mathrm{Kg}$. Each natural products were given to each group from the day of insertion of implant for about a month of healing period. Periotest machine was used to test the implant stability at the time of insertion and again after a month. The results showed that there was a significant difference in the primary and secondary stability of implant and these natural products could be potentially used as an adjunct. 29

Pain Management and Bone Healing after Implant Placement - In a randomised controlled clinical study, a total of 6 patients were divided into the study and control groups. Three patients in each group had either single or multiple implants placed. The study group was given CQ with no extra medication and routine analgesics and antibiotics was given to control group. It was found that pain and swelling were minimal in the study group and increased serum level of alkaline phosphatase contributed to improved bone healing. ${ }^{30}$

\section{In-Vitro Studies}

Antibacterial Activity - The anti-bacterial activity of CQ was evaluated in the management of skin and wound infections. A study by Mummad et al was intended to assess the in vitro antibacterial activity of methanolic concentrates of nine plants. Broth dilution methods and Agar well diffusion were utilized to determine the antibacterial action of 9 Ethiopian plants against four bacterial species including, Staphylococcus aureus, Klebsiella pneumoniae, Pseudomonas aeruginosa, and Escherichia coli. One among these plants was CQ. The concentrate of CQ demonstrated most noteworthy inhibitory activity against strains of $\mathrm{s}$. aureus. These investigations show that CQ can be utilized as an antibacterial agent. 31

\section{Osteoblast Differentiation}

Previous studies have reported that $\mathrm{CQ}$ as an antiosteoporotic agent. An invitro study by Tassaduq et al looks at the adequacy of CQ in advancing osteoblast differentiation of the murine pre-osteoblast cell line, MC3T3-E1. Ethanolic extract of CQ (CQ-E) was accounted for to influence growth kinetics of MC3T3-E1 cells in a dosage-dependent manner. CQ-E with high concentrations have reported adverse effects, whereas in lower concentrations it was found to be non-toxic and there was an increase in cell proliferation rate. CQ-E treatment conjointly increases the differentiation of osteoblasts, as reflected by an extensive increment in the expression of the early osteoblast marker alkaline phosphatase activity, and later stage, by mineralization of ECM compared to the control group. These findings suggest the low concentrations of CQ-E exhibits osteogenic properties. $^{32}$

\section{Enhanced Mesenchymal Stem Cell Proliferation}

Bhagath Kumar Potu et al assessed the impacts of the petroleum ether extract of CQ on the proliferation rate of BMMSCs, the differentiation of marrow mesenchymal stem cells into ECM calcification \& osteoblast. MSCs were cultured in media with or without CQ for about a month and were then stained for ALP. Von Kossa staining method was used as a confirmatory test for extracellular matrix calcification. Marrow-mesenchymal stem cells cultures in control media and osteogenic media supplemented with CQ extract (100, $200,300 \mu \mathrm{g} / \mathrm{mL}$ ) were also subjected to a cell proliferation assay (MTT). Treatment with 100, 200 or $300 \mu \mathrm{g} / \mathrm{mL}$ petroleum ether extract of CQ enhanced the differentiation of marrow mesenchymal stem cells into ALP-positive osteoblasts and increased extracellular matrix calcification. Here, $300 \mu \mathrm{g} / \mathrm{mL}$ petroleum ether extract of CQ showed increased proliferation rate of the marrow mesenchymal stem cells. High proliferation, differentiation, and calcification rate were seen in cells grown in osteogenic media containing CQ than control groups. Along these lines, CQ could be possibly utilized for the treatment of osteoporosis. ${ }^{33,12}$

\section{Animal Studies \\ Anti-Osteoporotic Activity \\ Bhagath et al studied the petroleum-ether extract of Cissus quadrangularis Linn in osteoporotic rat model. In this investigation, female Wistar rodents were isolated into four groups of six each. Except group 1, all the other groups were ovariectomized. Group 1 was sham operated, Group 2 is ovariectomized control group (ovx) given equivolume of}


saline, Group 3 - raloxifene $(5.4 \mathrm{mg} / \mathrm{kg}$ ) and Gathering 4 oil ether concentrate of CQ $(500 \mathrm{mg} / \mathrm{kg}$ ) for a period of 3 months. The findings were assessed based on morphology of the femur, weight of an animal, and histochemical localization of alkaline phosphatase and tartrate-resistant acid phosphatase (TRAP) in femur bone. Here, CQ group showed reduced bone loss in comparison with OVX group. There was increased weight gain in femur bone, and furthermore reduced osteoclastic activity there by encouraging bone formation. The bone formation was assessed by ALP staining \& osteoclastic activity was confirmed by TRAP staining. Image analysis software was used to evaluate the colour intensity of ALP and TRAP enzymes. The CQ was seen successful on both enzymes, and can be utilized prevention and treatment of postmenopausal osteoporosis. $^{34}$

\section{Wound Healing}

Ayesha et al conducted an animal study to investigate the wound healing efficiency of herbal gel containing the ethanolic extract of CQ on Wistar Albino rats. Groups were topical application of $20 \%$ Ethanolic extract of Cissus quadrangularis ethosomal gels (CQSG), $40 \%$ Ethanolic extract of CQSG and standard/marketed ointment i.e., Mebo ointment. It was concluded that ethosomal gel formulation containing $40 \%$ ethanolic extract of CQ was found to be the best gel for wound healing activity. ${ }^{35}$

\section{Clinical Studies \\ Fracture Healing}

Nimisha et al studied the osteogenic potential of CQ in fracture healing. In this study a total of 60 patients were divided in to two groups with simple mandibular fracture. Group 1 includes two capsules of CQ (one capsule consists of $300 \mathrm{mg}$ of CQ) B.D, Group 2 includes two capsules placebo (starch powder) B.D. The radiographic and clinical analysis suggested that fracture healing was better with CQ. Western blot analysis was used for all the samples in group 1 for osteopontin expression and flow cytometry shows higher levels of expression of osteopontin protein and CD4 + T cells expressing osteopontin, respectively. The investigation reasoned that CQ quickens healing of fracture and causes early remodelling of fracture callus; in this way, it tends to be used for quicker and improved fracture healing along with advanced surgical technique of fracture management. 36 The effect of CQ \& Tulsi, in healing of mandibular fractures, the results showed that period of immobilization was the least in Tulsi when compared to CQ by Mohammed et al. ${ }^{37}$

\section{Osteoporosis}

Colle's fracture is commonly found in people above 40 yrs. of age and is particularly seen in women because of postmenopausal osteoporosis and occurs at the distal end of the radius at the corticocancellous junction. In a study reported by Siddaram et al, 30 patients with Colle's fracture were selected and randomly divided in following 3 groups of 10 patients each, Group A- external application, Group Binternal application and Group C - both external and internal application of Cissus quadrangularis Linn. The results concluded that the combined therapy of internal and external application was most effective. ${ }^{38}$

\section{CONCLUSIONS}

This review has discussed in detail about CQ, its pharmacological actions and applications. This natural product has shown good applications in general medical field. In dentistry, it has been used for bone regeneration in implant and fracture healing. In future, CQ can be tried for various applications in bone regeneration after endodontic surgery and dentin pulp tissue regeneration in revascularization procedure.

Financial or Other Competing Interests: None.

\section{REFERENCES}

[1] EL-Kamali HH, EL-Amir MY. Antibacterial activity and phytochemical screening of ethanolic extracts obtained from selected sudanese medicinal plants. Current Res J Bio Sci 2010;2(2):143-6.

[2] Rajan S, Thirunalasundari T, Jeeva S. Anti-enteric bacterial activity and phytochemical analysis of the seed kernel extract of Mangifera indica Linnaeus against Shigella dysenteriae (Shiga, corrig.) Castellani and Chalmers. Asian Pac J Trop Med 2011;4(4):294-300.

[3] Rajpal V. Standardization of Botanicals. Vol. 1. Eastern Publishers 2005:77-81.

[4] Sen MK, Dash BK. A review on phytochemical and pharmacological aspects of Cissus quadrangularis L. Inter J Green Pharmacy 2012;6(3):169-73.

[5] Chatterjee A, Prakrashi SC. The treatise on Indian medicinal plants. Vol. 3. Publications \& Information Directorate 1994:173-4.

[6] Kumbhojkar MS. et al. Ethanobotany of Cissus quadrangularis Linn from India. Ethanobotany 1991;3:21-5.

[7] Singh KK, Maheshwari JK. Traditional phytotherapy amongst the tribals of Varanasi district, Uttar Pradesh [1983]. Journal of Economic and Taxonomic Botany 2013;4(3):829-38.

[8] Singh G, Rawat P, Maurya R. Constituents of Cissus quadrangularis. Nat Prod Res 2007;21(6):522-8.

[9] Aswar UM, Bhaskaran S, Mohan V, et al. Estrogenic activity of friedelin rich fraction (IND-HE) separated from Cissus quadrangularis and its effect on female sexual function. Pharmacognosy Res 2010;2(3):138-45.

[10] Jainu M, Devi CSS. Effect of Cissus quadrangularis on gastric mucosal defensive factors in experimentally induced gastric ulcer-a comparative study with sucralfate. J Med Food 2004;7(3):372-6.

[11] Chidambara Murthy KN, Vanitha A, Mahadeva Swamy M, et al. Antioxidant and antimicrobial activity of Cissus quadrangularis L. J Med Food 2003;6(2):99-105.

[12] Potu BK, Bhat KMR, Rao MS, et al. Petroleum ether extract of Cissus quadrangularis (Linn.) enhances bone marrow mesenchymal stem cell proliferation and facilitates osteoblastogenesis. Clinics (Sao Paulo) 2009;64(10):9938. 
[13] Bhujade AM, Talmale S, Kumar N, et al. Evaluation of Cissus quadrangularis extracts as an inhibitor of COX, 5LOX, and proinflammatory mediators. J Ethnopharmacol 2012;141(3):989-96.

[14] Vijay P, Vijayvergia R. Analgesic, anti-inflammatory and antipyretic activity of Cissus quadrangularis. Journal of Pharmaceutical Science and Technology 2010;2(1):1118.

[15] Swamy AHMV, Kulkarni RV, Thippeswamy AHM, et al. Evaluation of hepatoprotective activity of Cissus quadrangularis stem extract against isoniazid-induced liver damage in rats. Indian J Pharmacol 2010;42(6):397400.

[16] Srivastava AK, Srivastava P, Mishra JN, et al. Antidiabetic activity of the stem extracts of Cissus quadrangularis Linn. J Pharm Res 2011;4(11):3873-4.

[17] Balasubramanian $P$, Jayalakshmi K, Vidhya $N$, et al. Antiviral activity of ancient system of ayurvedic medicinal plant Cissus quadrangularis L. (Vitaceae). J basic Clin Pharm 2010;1(1):37-40.

[18] Kashikar ND, George IA. Antibacterial activity of Cissus quadrangularis Linn. Indian Journal of Pharmaceutical Sciences 2006;68(2):245.

[19] Somova LI, Shode FO, Ramnanan P, et al. Antihypertensive, antiatherosclerotic and antioxidant activity of triterpenoids isolated from Olea europaea, subspecies africana leaves. J Ethnopharmacol 2003;84(23):299-305.

[20] Oben JE, Enyegue DM, Fomekong GI, et al. The effect of Cissus quadrangularis (CQR-300) and a Cissus formulation (CORE) on obesity and obesity-induced oxidative stress. Lipids Health Dis 2007;6:4.

[21] Subhashri S, Vedha Hari BN, Ramya Devi D. Pharmacological activities based on different extracts of Cissus quadrangularis. IJPPR 2013;5(2):128-33.

[22] Sudharameshwari K, Maheshwari V. Cissus quadrangularis extract mediated green synthesis of silver nanoparticles: pharmacological applications. Indian J Med Res Pharm Sci 2017;4(8):30-6.

[23] Bloomer RJ, Farney TM, McCarthy CG, et al. Cissus quadrangularis reduces joint pain in exercise-trained men: a pilot study. Phys Sportsmed 2013;41(3):29-35.

[24] Udupa KN, Prasad GC. Cissus quadrangularis in healing of fractures. A clinical study. J Indian Med Assoc 1962;38:590-3.

[25] Prasad GC, Udupa KN. Effect of cissus quadrangularis on the healing of cortisone treated fractures. Indian J Med Res 1963;51:667-76.
[26] Udupa KN, Prasad GC. Further studies on the effect of cissus quadrangularis in accelerating fracture healing. Indian J Med Res 1964;52:26-35.

[27] Oben JE, Ngondi JL, Momo CN, et al. The use of a Cissus quadrangularis/Irvingia gabonensis combination in the management of weight loss: a double-blind placebocontrolled study. Lipids Health Dis 2008;7:12.

[28] Lal N, Dixit J. Biomaterials in periodontal osseous defects. J Oral Biol Craniofac Res 2012;2(1):36-40.

[29] Al-Sultan MMH, Al-Khatib AR. The effect of natural products extract on stability of orthodontic implant: an experimental study. International Journal of Scientific \& Engineering Research 2015;6(1):289-94.

[30] Managutti AM, Shah DN, Patel JC, et al. Evaluation of clinical efficacy of Cissus quadrangularis in pain management and bone healing after implant placement: a pilot study. Int J Oral Implantol Clin Res 2015;6(2):35-9.

[31] Sabo I, Zakariya AM, Ahmed A, et al. Antibacterial studies on stem-bark of Lannea barteri (OLIV.) ENGL. (ANACARDIACEA). FUW Trends in Science \& Technology Journal 2019;4(1):122-5.

[32] Tasadduq R, Gordon J, Al-Ghanim KA, et al. Ethanol extract of Cissus quadrangularis enhances osteoblast differentiation and mineralization of murine preosteoblastic MC3T3-E1 cells. J Cell Physiol 2017;232(3):540-7.

[33] Potu BK, Rao MS, Nampurath GK, et al. Evidence-based assessment of antiosteoporotic activity of petroleumether extract of Cissus quadrangularis Linn. on ovariectomy-induced osteoporosis. Ups J Med Sci 2009;114(3):140-8.

[34] Banu J, Varela E, Bahadur AN, et al. Inhibition of bone loss by Cissus quadrangularis in mice: a preliminary report. J Osteoporos 2012;2012:1-10.

[35] Siddiqua A, Mittapally S. Formulation and evaluation of ethanolic extract of Cissus quadrangularis herbal gel. IRJPBS 2017;4(4):9-29.

[36] Singh N, Singh V, Singh RK, et al. Osteogenic potential of cissus qudrangularis assessed with osteopontin expression. Natl J Maxillofac Surg 2013;4(1):52-6.

[37] Mohammad S, Pal US, Pradhan R, et al. Herbal remedies for mandibular fracture healing. Natl J Maxillofac Surg 2014;5(1):35-8.

[38] Siddaram A, Neetu J, Uttam N, et al. Management of Colle's fracture By Asthishrankhala (Cissus quadrangularis Linn): a clinical study. IRJP 2012;3(10):164-8. 